\title{
A Theory of Learning for the Mobile Age (pre-print)
}

\author{
Mike Sharples, Josie Taylor, Giasemi Vavoula
}

\begin{abstract}
'A society which is mobile, which is full of channels for the distribution of a change occurring anywhere, must see to it that its members are educated to personal initiative and adaptability. Otherwise, they will be overwhelmed by the changes in which they are caught and whose significance or connections they do not perceive.' Dewey (1916, p. 88)
\end{abstract}

When John Dewey wrote Democracy and Education, the industrialised world was undergoing a huge technological and social disruption. Railways and paved roads had enabled mass travel, wireless communication had bridged the Atlantic, and a mechanised war was being fought across continents. Today, we are experiencing similar social and technological disruption, with the Internet and mobile technologies providing global access to information and mobility of knowledge. Ten years ago a school in Russia teaching English had no access to contemporary language sources; now it has the worldwide web. Five years ago, a farmer in rural Kenya had no communication with the nearest city, now he carries a mobile phone. We live in a society in which the "channels for distribution of change" are carried with us as part of daily life.

Every era of technology has, to some extent, formed education in its own image. That is not to argue for the technological determinism of education, but rather that there is a mutually productive convergence between the main technological influences on a culture and the contemporary educational theories and practices. Thus, in the era of mass print literacy, the textbook was the medium of instruction, and a prime goal of the education system was effective transmission of the canons of scholarship. During the computer era of the past fifty years, education has been re-conceptualised around the construction of knowledge through information processing, modelling and interaction (Duffy \& Cunningham, 1996). Now, as we enter a new world of global digital communication, it is no surprise that there is a growing interest in the relations between mobile technology and learning. What we need, however, is an appropriate theory of education for the mobile age.

Many theories of learning have been advanced over the 2500 years between Confucius and the present day, but almost all have been predicated on the assumption that learning occurs in a school classroom, mediated by a trained teacher. A few educational thinkers have developed theory-based accounts of learning outside the classroom, including Argyris (Argyris \& Schön, 1996), Friere (Freire, 1996), Illich (Illich, 1971), and Knowles (Knowles \& Associates, 1984), but none have put the mobility of learners and learning as the focus of enquiry.

Our aim is to propose a theory of learning for a mobile society. It encompasses both learning supported by mobile devices such as cellular (mobile) phones, portable computers and personal audio players, and also learning in an era characterised by mobility of people and knowledge (Rheingold, 2002) where the technology may be 
embedded in fixed objects such as 'walk up and use' information terminals. For brevity we shall refer to these together as mobile learning.

\section{Criteria for a theory of mobile learning}

A first step in postulating a theory of mobile learning is to distinguish what is special about mobile learning compared to other types of learning activity. The obvious, yet essential, difference is that it starts from the assumption that learners are continually on the move. We learn across space as we take ideas and learning resources gained in one location and apply or develop them in another. We learn across time, by revisiting knowledge that was gained earlier in a different context, and more broadly, through ideas and strategies gained in early years providing a framework for a lifetime of learning. We move from topic to topic, managing a range of personal learning projects, rather than following a single curriculum. We also move in and out of engagement with technology, for example as we enter and leave cell (mobile) phone coverage (Vavoula \& Sharples 2002).

To portray learning as a labile activity is not to separate it from other forms of educational activity, since some aspects of informal and workplace learning are fundamentally mobile in the ways outlined above. Even learners within a school will move from room to room and shift from topic to topic. Rather, it illuminates existing practices of learning from a new angle. By placing mobility of learning as the object of analysis we may understand better how knowledge and skills can be transferred across contexts such as home and school, how learning can be managed across life transitions, and how new technologies can be designed to support a society in which people on the move increasingly try to cram learning into the gaps of daily life.

Second, a theory of mobile learning must therefore embrace the considerable learning that occurs outside offices, classrooms and lecture halls. A study by Vavoula (2005) of everyday adult learning for the MOBIlearn project, based on personal learning diaries, found that almost half (49\%) of the reported learning episodes took place away from home or the learner's own office, i.e. the learner's usual environment. The learning occurred in the workplace outside the office $(21 \%)$, outdoors $(5 \%)$, in a friend's house $(2 \%)$, or at places of leisure $(6 \%)$. Other locations reported $(14 \%)$ included places of worship, the doctor's surgery, cafes, hobby stores, and cars. There was no consistent relation between the topic of learning and the location of learning. An example of a connection between location and learning was a person learning the names of different kinds of foreign beer in a pub while conversing with friends. An example of no connection was a person discussing with a colleague over coffee at a bar and discovering references related to their work.

A central concern must be to understand how people artfully engage with their surroundings to create impromptu sites of learning. For example (from Vavoula's diary studies), a person wants to learn how to pre-program a video recorder and so creates a context for learning out of a recorder, a television and a friend with some knowledge of video technology who offers explanations and clarifications.

Third, to be of value, a theory of learning must be based on contemporary accounts of practices that enable successful learning. The US National Research Council produced 
a synthesis of research into educational effectiveness across ages and subject areas (National Research Council, 1999). It concluded that effective learning is:

- learner centred: it builds on the skills and knowledge of students, enabling them to reason from their own experience.

- knowledge centred: the curriculum is built from sound foundation of validated knowledge, taught efficiently and with inventive use of concepts and methods.

- assessment centred: assessment is matched to the ability of the learners, offering diagnosis and formative guidance that builds on success.

- community centred: successful learners form a mutually promotive community, sharing knowledge and supporting less able students.

These findings broadly match a social-constructivist approach, which views learning as an active process of building knowledge and skills through practice within a supportive group or community (for an overview, see Kim, 2000). Learning involves not only a process of continual personal development and enrichment, but also the possibility of rapid and radical conceptual change (see Davis, 2001).

Lastly, a theory of mobile learning must take account of the ubiquitous use of personal and shared technology. In the UK, over $75 \%$ of the general population and $90 \%$ of young adults own mobile phones (Crabtree, Nathan, \& Roberts, 2003). These figures mask the huge disparities in access to technology around the world, but they indicate a trend towards ownership of at least one, and for some people two or three, items of mobile technology including mobile phones, cameras, music players and portable computers. A trend relevant to a theory of learning in the mobile world is that some developing countries, particularly in sub-Saharan Africa, are by-passing fixed network telephony to install mobile phone networks in rural areas. These offer the opportunity for people in rural communities not only to make phone calls, but to gain the advantages of mobile services such as text and multimedia messaging. For example, a project in Kenya is employing text messaging to coordinate in-service training of teachers (Traxler, 2005).

We are now seeing a well-publicised convergence of mobile technologies, as companies design and market mobile computer-communicators, combining into a single device the functions of phone, camera, media player and multimedia wireless computer. Another equally important convergence is occurring between the new personal and mobile technologies and the new conceptions of learning as a personally-managed lifelong activity (Table \#.1).

\begin{tabular}{cc}
\hline New Learning & New Technology \\
\hline Personalised & Personal \\
Learner centred & User centred \\
Situated & Mobile \\
Collaborative & Networked \\
Ubiquitous & Ubiquitous \\
Lifelong & Durable \\
\hline
\end{tabular}

Table \#.1 Convergence between learning and technology 
Just as learning is being re-conceived as a personalised and learner-centred activity (Leadbetter, 2005), so too are new digital technologies offering personalised services such as music play-lists and digital calendars. Just as learning can be seen as a situated and collaborative activity (Brown, Collins, \& Duguid, 1989), occurring wherever people, individually or collectively, have problems to solve or knowledge to share, so mobile networked technology can enable people to gain and share information wherever they have a need, rather than in a fixed location such as a classroom.

Computer technology, like learning, is ubiquitous -- computers are embedded in everyday devices such as photocopiers and televisions. Computing is also becoming more durable, in that although the hardware may last only for two or three years, personal software packages and storage formats (such as PDF) evolve through successive versions, with a large measure of backward compatibility. Personal technology now offers people the opportunity to preserve and organise digital records of their learning over a lifetime (Banks, 2004).

To summarise, we suggest that a theory of mobile learning must be tested against the following criteria:

- is it significantly different from current theories of classroom, workplace or lifelong learning?

- does it account for the mobility of learners?

- does it cover both formal and informal learning?

- does it theorise learning as a constructive and social process?

- does it analyse learning as a personal and situated activity mediated by technology?

From these general criteria we propose a tentative definition of mobile learning as 'the processes of coming to know through conversations across multiple contexts amongst people and personal interactive technologies'. We shall now attempt to unpack the definition, indicating how conversation and context are essential constructs for understanding mobile learning, and offering implications for the ownership of learning and the integration of mobile learning with conventional education.

The focus of our investigation is not the learner, nor their technology, but the communicative interaction between these to advance knowing. At a first level of analysis we shall make no distinction between people and technology, but explore the dynamic system that comprises people and technology in continual flux. We shall show how this leads to learning as a conversational process of becoming informed about each other's 'informings', to cognition as diffused amongst interactions and reciprocally constructed conversations, and context not as a fixed shell surrounding the learner, but as a construct that is shaped by continuously negotiated dialogue between people and technology. We shall indicate how this allows us to understand the ecologies of learning in a world of networked mobility. It also leads to intrinsic contradictions, relating to the ontological status of technology in learning and ownership of the means of communication. We suggest that we can only begin to resolve these contradictions by understanding the relationship between traditional and 
mobile learning, and by creating a society in which learning as a global conversation can be given a central role in our system of education.

\section{Learning as Conversation}

Central to our definition is the claim that conversation is the driving process of learning. It is the means by which we negotiate differences, understand each other's experiences and form transiently stable interpretations of the world. Dewey claimed that not only is social life identical with communication, but all communication (and hence all genuine social life) is educative:

To be a recipient of a communication is to have an enlarged and changed experience. One shares in what another has thought and felt and in so far, meagerly or amply, has his own attitude modified. Nor is the one who communicates left unaffected. ... Except in dealing with commonplaces and catch phrases one has to assimilate, imaginatively, something of another's experience in order to tell him intelligently of one's own experience. ... It may fairly be said, therefore, that any social arrangement that remains vitally social, or vitally shared, is educative to those who participate in it. (Dewey 1916, p. 5-6)

The problem with Dewey's claim is that it is unclear what he meant by the term 'communication'. On the one hand, a communication is a token that is sent and received ("to be the recipient of a communication"). On the other hand, communication is the sharing of experience ("one shares in what another has thought"). Freire (1996) refers to "co-intentional learning", where teacher and learner jointly develop understanding through dialogue.

The teacher is no longer merely the one-who-knows, but one who is himself taught in dialogue with the students, who in turn while being taught also teach. They become jointly responsible for a process in which all grow. (Freire, 1996, p. 61)

The description we give here of learning as conversation is primarily based on the work of Gordon Pask (Pask, 1976). It derives from cybernetics, the study of communication and control in natural and artificial systems, and its more recent extension to second order cybernetics, the study of the mechanisms by which a system can understand itself. This 'radical constructivism' (von Glaserfeld, 1984) extends the notion of learning as a constructive process beyond individuals to describe how distributed systems including teams, organisations and societies learn and develop. As an aside, there is a direct link between Freire and Pask, through the attempts by Stafford Beer (a colleague of Pask) and Fernando Flores (best known for his work with Terry Winograd on applying models of conversation to the design of a computer email system (Winograd \& Flores, 1987)) to create a national cybernetic communications network for Chile during the Allende government in the early 1970s.

Pask broke with the model of communication as the efficient transmission of information that has been a foundation both for communications technology (Shannon 
\& Weaver, 1949) and traditional education. With a prescience that foreshadows recent developments such as the Semantic Web (the development of the worldwide web into a knowledge-based medium (Berners-Lee, Hendler, \& Lassila, 2001)) and smart mobs (groups of interconnected people forming a distributed intelligence: (Rheingold, 2002)), Pask proposed a new conception of communication. Rather than seeing communication as the exchange of messages through an inert and transparent medium, he reconceived it as the sharing of understanding within a pervasive computational medium (Pask, 1975). Thus, media are active and responsive systems within which mind-endowed individuals converse.

The general approach makes no distinction between people and interactive systems such as computers, with the great advantage that the theory can be applied equally to human teachers and learners, or to technology-based teaching or learning support systems. The concomitant problem is that on its own the theory does not give sufficient importance to the unique moral and social worth of human learners in their interaction with technology. We shall address this issue later.

Pask's definition of a 'mind' was broad, to encompass any organisation expressed in a mutual language (able to accommodate commands, questions and instructions) that gives rise to thought, feeling and behaviour. This includes human minds, but also some computer programs, and even theatre scripts and political manifestos. Minds, by expressing language and instantiating different systems of belief, provide the impetus for conversation. For example, a political ideology instantiates a system of language and beliefs which, when expressed in a party manifesto, gives rise to debate and discussion. On a smaller scale, two children with different views of a shared phenomenon such as a physics experiment, and capable of expressing their views in a mutual language, engage in conversation to try and come to a shared interpretation.

Thus, conversation is not the exchange of knowledge, but the process of becoming informed about each other's 'informings' (what Pask described as the "coordination of coordinations of coordinations") (Scott, 2001). Higher level coordinations are 'tokens' for lower-level coordinations, (objects and events), which are themselves tokens for stabilities of sensori-motor activity and "structural coupling" with the environment. In order to constitute a 'conversation', the learner must be able to formulate a description of himself and his actions, explore and extend that description and carry forward the understanding to a future activity. In order to learn, a person or system must be able to converse with itself and others about what it knows.

Central to these learning conversations is the need to externalise understanding. To be able to engage in a productive conversation, all parties need access to a common external representation of the subject matter (an agreed terminology, and also notes, concept maps or other learning resources) that allows them to identify and discuss topics.

More recently, Pask's Conversation Theory has been applied by Laurillard (2002) and by Sharples (2003) to examine the processes of learning with technology. Learning requires more than transparent channels of communication and a means for transmitting knowledge; we also need a shared language (among learners, and between learners and computational systems), a means to capture and share phenomena, and a method of expressing and conversing about abstract representations 
of the phenomena. Learning is a continual conversation with the external world and its artefacts, with oneself, and also with other learners and teachers. The most successful learning comes when the learner is in control of the activity, able to test ideas by performing experiments, to ask questions, collaborate with other people, seek out new knowledge, and plan new actions (Ravenscroft, 2000).

Though primarily concerned with the application of educational technology to university-level teaching, the analysis by Laurillard (2002) can be applied more broadly across learning settings and subject areas. Figure \#.1 shows an adapted version of her framework for learning as conversation. Conversations can take place at two levels. At the Level of Actions, a learner and partner may converse about the performance of some educational activity, such as carrying out a scientific experiment, through discussion establishing a shared understanding of the phenomenon ("what's happening here?", "what do we do next?"), producing a cycle of setting goals and building and refining practical models to test those goals.

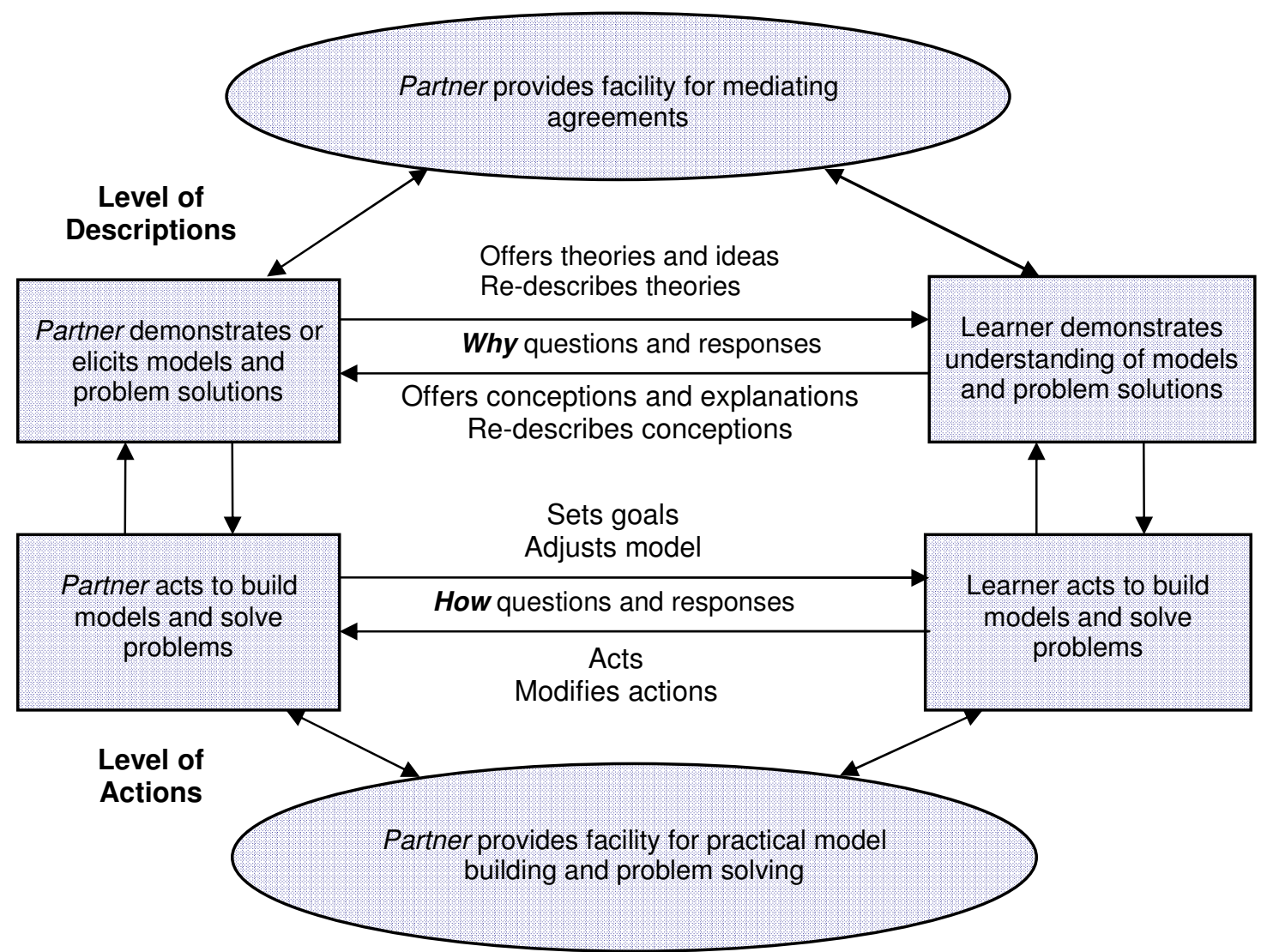

Figure \#.1 A Conversational Framework for Learning with Technology (adapted from Laurillard, 2002)

At the Level of Descriptions, the learner and partner discuss the implications of the actions, to make sense of the activity through a process of proposing and re-describing theories and offering and adjusting explanations ("why did that happen?", "what does this mean?"). They may also be informing each other of their viewpoints ("I think its 
because...") in order to uncover differences in conception or experience and so move towards a shared understanding. These conversations can be mediated by external representations to assist the learners in negotiating agreements, such as lab notebooks or shared concept maps. In addition to these external conversations, each learner holds a continual internal dialogue, making sense of concrete activity by mental abstraction and by forming theories and testing them through actions in the world.

It should be emphasised that the conversational framework is not a normative lesson plan, but a means to describe the process of coming to know through conversation. Laurillard proposes that for learning to succeed, the student must:

- apprehend the structure of the discourse

- interpret the forms of representation

- act on descriptions of the world

- adjust actions to fit the task goals

- adjust descriptions to fit the topic goal

- reflect on the cycle of goal, action, feedback

Some educational activities, such as science lab classes, are explicitly designed to support this structure of conversation. Most conversations, though, cover only one part of the framework, either because the learner has no conversational partner available, or there are no tools for model building to hand, or learners lack the language and concepts to converse at the level of descriptions. That is where technology can assist. The conversational framework shows a conversation between learner and partner. The partner may be a teacher, or another learner, or it may be computer interactive technology.

Technology may take the place of the teacher, as in drill and feedback. The difficulty here is that the computer can hold a limited dialogue at the level of actions: "look here"; "what's this?"; "do that", but is not able to reflect on its own activities or its own knowledge. Although some 'intelligent tutoring systems' have been developed which attempt to model the student and to tailor feedback to the perceived student needs, the computer is not engaging in developing a shared understanding. And because it cannot hold a conversation at the level of descriptions, it has no way of exploring students' misconceptions or helping them to reach a shared understanding.

The technology may provide or enrich the environment in which conversations take place. It can provide tools for collecting data and for building and testing models. It can extend the range of activities and the reach of a discussion, into other worlds through games and simulations, and to other parts of this world by mobile phone or email. The technology provides a shared conversational learning space, which can be used not only for single learners but also for learning groups and communities. Technology can also demonstrate ideas or offer advice at the level of descriptions, as with the worldwide web or online help systems, or through specific tools to negotiate agreements, such as concept maps and visualisation tools.

In all these conversations (among learners and teachers, between learners and interactive technology) there is a fundamental need to establish and sustain a language that can enable shared understanding. One means to do this is through 'teachback' (a term coined by Pask) where one person attempts to re-describe what they have 
learned, to check if it matches the understanding of the other participants in the conversation. This can form part of deliberate learning or can occur naturally, for example when we repeat back a set of instructions over the telephone. It does not mean that every concept must be negotiated and agreed. Such rigour rarely occurs in practice, and pinning down the meaning of terms can often be counter-productive. Not only can debate over the meaning of language stifle discussion, but social solidarity can often be fostered by ignoring precision (Boyd \& Pask, 1987).

So far we have described conversations for learning as taking place in the abstract, but every human partner to a conversation (though not necessarily every computational partner) is situated in one physical location. A significant problem with conversations in a mobile world is that not only does the language of communication need to be continually negotiated, but also its context.

\section{Context and learning}

All activity is performed in context. Cole (1996) makes an important distinction between context as "that which surrounds us" and context as "that which weaves together". This mirrors the distinction made in the technical literature on pervasive computing between context as a 'shell' that surrounds the human user of technology and context as arising out of the constructive interaction between people and technology.

The 'context as shell' model, exemplified by the Shannon-Weaver (op. cit.) informational model of communication, situates the learner within an environment from which the senses continually receive data that are interpreted as meaningful information and employed to construct understanding. Thus, a learner in a classroom may receive information from a teacher, a whiteboard and a text book, all of which must be assimilated and integrated to form a composite understanding of the topic being studied.

But learning not only occurs in a context, it also creates context through continual interaction. The context can be temporarily solidified, by deploying or modifying objects to create a supportive workspace, or forming an ad hoc social network out of people with shared interests, or arriving at a shared understanding of a problem. But context is never static. The common ground of learning is continually shifting as we move from one location to another, gain new resources, or enter new conversations (Lonsdale et al., 2003).

Traditional classroom learning is founded on an illusion of stability of context, by setting up a fixed location with common resources, a single teacher, and an agreed curriculum that allows a semblance of common ground to be maintained from day to day. If all these are removed, as may be the case with learning in the mobile age, then creating temporary islands of relatively stable context is a central concern. In this respect, the historic construction of context, the process by which we arrive at current understanding, assumes greater importance.

Current activity can only be fully understood by taking an historical perspective, to understand how it has been shaped and transformed by previous ideas and practices 
(Engeström, 1996). This is particularly true of mobile learning, where both the immediate history of activity and the wider historical process of coming to know merge to create new understanding. For example, a visitor to an art gallery stands in front of a painting. She has arrived at a current understanding of the painting from the path she has taken through the gallery - taking in the ambience, stopping at other paintings, reading the guidebook - and also from a lifetime of creating and interpreting works of art starting with childhood drawings. In one sense, context can be seen as an ever-playing movie, with each frame of current context being a progression from earlier ones and the entire movie being a resource for learning. But it is a movie that is continually being constructed by the cast, from moment to moment, as they share artefacts and create mutual understanding through conversation.

\section{The dialectical relationship between learning and technology}

We have characterised learning as a process of coming to know through conversation across continually re-constructed contexts. Now, we turn to the role of computer and communications technology in that process. The study by Vavoula (op. cit.) showed that $52 \%$ of everyday learning episodes involved one or more pieces of electronic technology: mobile and fixed phones, laptop and desktop computers, televisions and video recorders. To support mobile learning according to our definition, it is not necessary that the device itself be portable. Our definition of mobile learning embraced both learning with portable technology, and also learning in an era characterised by mobility of people and knowledge. Vavoula's studies showed that people create settings for learning out of technology or resources that are ready-tohand. For example, a person driving out of London in their car with a partner finds out about alternative ways of getting to London by train through on-street advertisement displays. Currently, these two aspects of mobile learning (learning with portable devices and learning while mobile) are somewhat separate but they are starting to converge, as handheld and wearable devices interact with their surroundings and static objects respond to people on the move. Thus, in the Caerus project (Naismith, Sharples \& Ting, 2005) visitors to the University of Birmingham botanic gardens were given handheld location (GPS) devices that automatically offered audio commentary on the flowers and shrubs as they walked around the gardens. Conversely, museum visitors can wear 'active badges' that identify them to the fixed exhibits and displays, which provide information displays tailored to their interests (Bristow et al., 2002). In the future, people may be able to create ad hoc spaces for individual or shared learning, deploying a combination of mobile and fixed technology, for example in homes, tourist locations or hotel lobbies (Sharples, 2003b).

A paradox arises from this analysis. In order to understand the complexity of learning we need to analyse a distributed system in which people and technology interact to create and share meaning. But putting people on a par with computers and phones fails to take account of the unique learning needs and moral worth of each individual person. We have attempted to address this paradox by describing the activity system of mobile learning, in a way that problematizes the dialectical relationship between people and technology. The analysis draws on cultural-historical activity theory as it applies to learning (Daniels, 2001) through an adapted version of Engeström's expansive activity model (Engeström, 1987). 


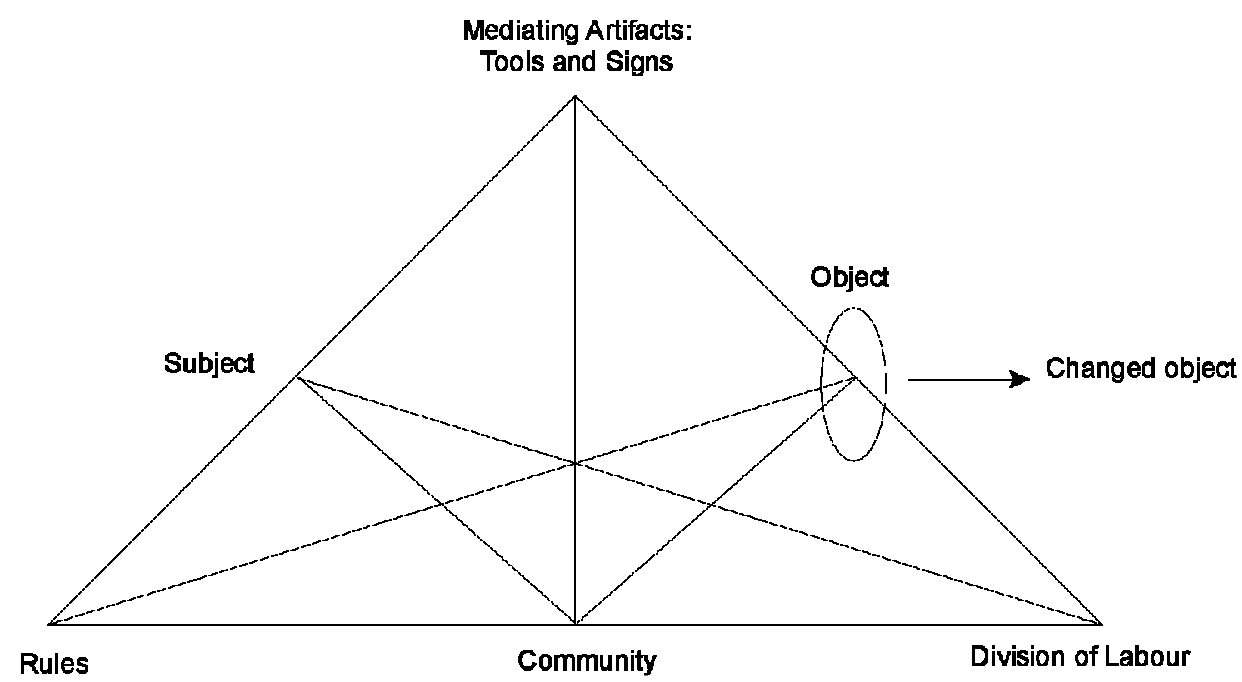

Figure \#.2 Engeström's expansive activity model

As with Pask's Conversation Theory, the model (Figure \#.2) describes a system of activity amongst interacting actors, showing the structural properties of the system. In the model, the subject is the focus of analysis (applied to learning systems, the subject is typically a learner). The object refers to the material or problem at which the activity is directed. This is shaped and transformed into outcomes through physical and symbolic, external and internal mediating instruments, including both tools and signs. The community comprises multiple individuals and/or sub-groups who share the same general object and who construct themselves as distinct from other communities. The division of labour refers to both the horizontal division of tasks between the members of the community and to the vertical division of power and status. Finally, the rules refer to the explicit and implicit regulations, norms and conventions that constrain actions and interactions within the activity system.

Following Engeström, we analyse learning as a cultural-historical activity system, mediated by tools that both constrain and support the learners in their goals of transforming their knowledge and skills. However, to explain the role of technology in learning we separate two perspectives, or layers, of tool-mediated activity. The semiotic layer describes learning as a semiotic system in which the learner's objectoriented actions (i.e. actions to promote an objective) are mediated by cultural tools and signs. The learner internalizes public language, instantiated in writing and conversation, as private thought which then provides the resource for control and development of activity (Vygotsky, 1978). The technological layer shows learning as an engagement with technology, in which tools such as computers and mobile phones function as interactive agents in the process of coming to know, creating a humantechnology system to communicate, to mediate agreements between learners (as with spreadsheets, tables and concept maps) and to aid recall and reflection (as with weblogs and online discussion lists). 


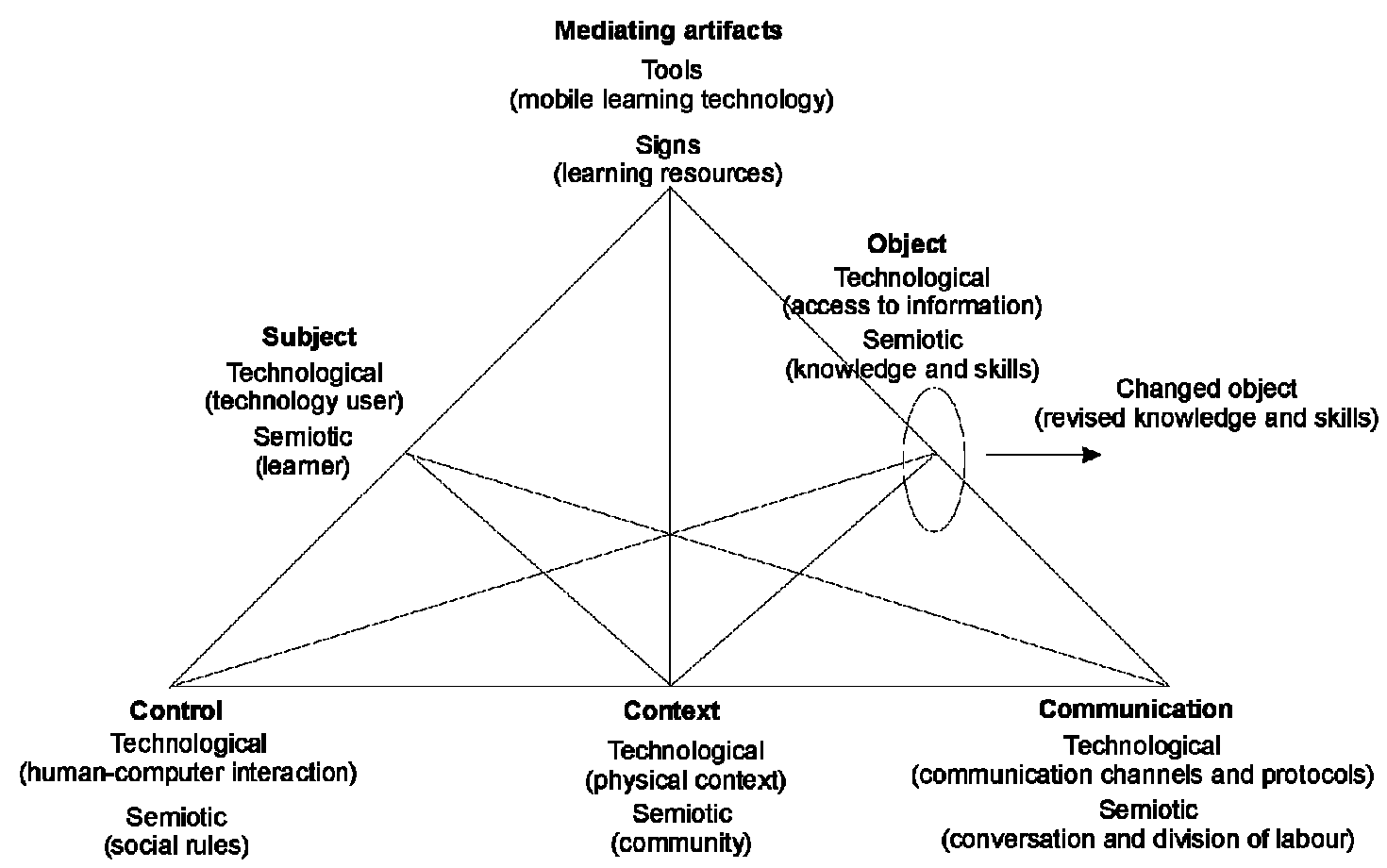

Figure \#.3 A Framework for analysing mobile learning.

These layers can be prised apart, to provide either a semiotic framework to promote discussion with educational theorists to analyse the activity and discourse of mobile learning, or a technological framework for software developers and engineers to propose requirements for the design and evaluation of new mobile learning systems. Or the layers can be superimposed (as in Figure \#.3), to examine the holistic system of learning as interaction between people and technology. Here, the semiotic fuses into the technological to form a broader category of technology than physical artefacts. Following Dewey (Hickman, 1990), we could describe technology from the merged perspective as any tool that serves the purpose of enquiry, enabling people to address problems in context and to clarify and transform them into new understanding. Thus, hammers, computers, languages and ideas may all qualify as technologies for enquiry, and there is no clear distinction between the semiotic and the technological.

We need to make clear that, for our framework, we are neither proposing the separation of the semiotic and the technological, nor the fusing of the two. Rather, we want to set up a continual dynamic in which the technological and the semiotic can be moved together and apart, creating an engine that drives forward the analysis of mobile learning.

Learning occurs as a socio-cultural system, within which many learners interact to create a collective activity framed by cultural constraints and historical practices. Engeström analyses the collective activity through an expanded framework that shows the interactions between tool-mediated activity and the cultural Rules, Community and Division of Labour. As we have adapted Engeström's framework to show the dialectical relationship between technology and semiotics, so we have taken the liberty to rename the cultural factors with terms - Control, Context and 
Communication - that could be adopted either by learning theorists or by technology designers. The terminology is important. Engeström's terms were drawn from a Marxist lexicon of cultural-historical materialism. We would suggest that these terms may hinder rather than assist dialogue between educational theorists and technology designers, so we have adopted related terms that are in the currency of both professions. Of course, this risks the possibility that the terms will be interpreted differently by both groups and simply lead to misunderstanding and mutual incomprehension, so we shall attempt to clarify their meaning.

\section{Control}

The control of learning may rest primarily with one person, usually the teacher, or it may be distributed among the learners. Control may also pass between learners and technology, for example in a dialogue for computer-based instruction. The technological benefit derives from the way in which learning is delivered: whether the learners can access materials when convenient, and whether they can control the pace and style of interaction. These are issues of human-computer interaction design.

However, technology use occurs within a social system of other people and technologies. Social rules and conventions govern what is acceptable (e.g. how to use e-mail, who is allowed to email whom, what kinds of document format should be used). A person's attitudes to technology can be influenced by what others around them think about it, for example, whether they are resentful at having to use the technology or are keen and eager to try it out. Individuals and groups can also express informal rules about the ways they like to work and learn.

\section{Context}

As we have proposed earlier, the context of learning is an important construct, but the term has many connotations for different theorists. From a technological perspective there has been debate about whether context can be isolated and modelled in a computational system, or whether it is an emergent and integral property of interaction (see for example Lonsdale, Baber and Sharples (2004) who describe an interactional model of context for mobile learning). Context also embraces the multiple communities of actors (both people and interactive technology) who interact around shared objectives, mutual knowledge, orientations to study, styles and strategies of learning.

\section{Communication}

The dialectical relationship between the technological and semiotic layers is perhaps the easiest to see in relation to Communication. If a technological system enables certain forms of communication (such as email or texting), learners begin to adapt their communication and learning activities accordingly. For example people are increasingly 'going online' at home, creating networks of interaction through phone conversation, texting, email and instant messaging that merge leisure and work activities into a seamless flow of conversation. As they become familiar with the technology they invent new ways of interacting - 'smilies', text message short forms, the language of instant messaging - that create new rules and exclusive communities (Grinter \& Eldridge, 2001).

This appropriation of technology not only leads to new ways of learning and working, it also sets up a tension with existing technologies and practices. For example, 
children can subvert the carefully managed interactions of a school classroom by sending text messages hidden from the teacher. On a broader scale, technology companies see markets for new mobile technology to support interactions such as file sharing and instant messaging.

\section{Dialectical relations and appropriation}

We propose that there is a dialectical relationship between nodes in the two planes of the mobile learning framework. This enables us to represent something of the process of appropriation that occurs when people are using technology to support their learning. Waycott (2004) provides an account of the internal workings of this process. When faced with a new tool, people examine both the possibilities and constraints it offers. This leads to a process in which the users adjust the 'fit' of their tools to their activities. Sometimes tools will cause their users to change their own behaviour to accommodate a feature or shortcoming in the tool; sometimes users will shape the tool to suit their specific requirements. Doing either of these things may initiate further changes as the users begin to exploit the technology, hence the dialectical nature of the process.

Thus, there is a continual co-evolution of technology and human learning (Bruckman, 2004), with individuals, groups and societies simultaneously developing new modes of interacting with technology (such as text messaging) in parallel with adopting new patterns of learning (such as just-in-time learning and mobile collaborative learning). Each new development in either learning or technology creates pressures that drive the next innovation. This is characteristic of activity systems, which evolve over lengthy periods of time, and are not simply reducible to actions, as Engeström points out:

Activity is a collective, systemic formation that has a complex mediational structure. An activity system produces actions and is realized by means of actions. However, activity is not reducible to actions. Actions are relatively short-lived and have a temporally clear-cut beginning and end. Activity systems evolve over lengthy periods of socio-historical time, often taking the form of institutions and organizations. (See Note 1)

Furthermore, activity systems are in perpetual flux with movement between the nodes of a given system, and between one activity system and another. This dialectical shaping can emerge at various nodes in the activity framework and provides the process that binds its two levels together.

\section{A case study of mobile learning}

To illustrate how our theory of mobile learning relates to real activity, we draw upon our experience in a large, multinational, European-funded research project, MOBIlearn (IST-2001-37440). The aim of the project was to define what functions and services a pedagogically sound mobile learning environment would need to be effective, and to implement and evaluate a system delivered on currently available mobile technologies (Da Bormida, Bo, Lefrere and Taylor, 2003; Taylor, 2004). The project used several scenarios to investigate learning in mobile environments, and we 
use one of these, the Museum Scenario, to illustrate the use of the mobile learning framework described above.

The purpose of the following discussion is not to report the evaluation of the trial. Selected elements of the data are used to illustrate the use of the framework, and the value of representing these to enable conversations between the various stakeholders: educators, pedagogy experts, system designers, technical implementers, museum curators and so on. To set the scene, we provide an overview of the trial.

\section{Background to the Museum Trial}

The first MOBIlearn trial took place in the Uffizi Gallery in Florence in December 2004 (Brugnoli, Bo and Murelli, 2005) in two galleries:

- The 'Leonardo Gallery', containing 11 canvases including 'The Adoration of the Kings' and 'Annunciation', by Leonardo Da Vinci

- The 'Botticelli Gallery', containing 19 canvases including 'Allegory of Spring' and 'The Birth of Venus' by Sandro Botticelli.

It is important to bear in mind certain specific characteristics of the Uffizi and of the two galleries used for the trial:

- the Uffizi provides very little information for visitors (just the name of the painting, the date and artist's name);

- the Uffizi is a spacious environment that does not always appear to have a rational layout. Most galleries are larger than $100 \mathrm{~m}^{2}$;

- the Uffizi displays a very large number of artworks in each gallery, this is especially true for the Botticelli Gallery;

- the gallery displays a huge number of works which, although wellknown to the general public, are complex and hard to interpret.

A variety of devices, all incorporating the MOBIlearn system were available, which included mobile phones, Personal Digital Assistants (PDAs), pocket PCs and notebook computers.

Participants were free to walk around the two galleries, inspecting the paintings, using one of these devices to find out more about them, and to communicate with one another. Altogether, 28 participants took part in the trials, in three groups. The groups were a group of 'foreign' (i.e. non-Italian) students; a group of Italian students and members of the 'Amici degli Uffizi' (Friends of the Uffizi), who played the part of art experts.

During the Uffizi trial, both qualitative and quantitative methods of data collection were used (see Brugnoli et al, op cit. for more detail). The following extracts from the initial evaluation report provide an interesting mix of semiotic and technical detail which we will analyse with reference to the mobile learning framework. 


\section{Age-related attitudes}

Young participants: Participants in this group appeared to be the most satisfied, using the system extensively, and adopting a playful, interactive approach. The general feeling of these participants was that the trial provided an opportunity for dynamic learning. They frequently returned to works they had already seen, exploring first the rooms and then the system. They were interested in "harnessing ...making the most of" the content offered by the system. "I really like it. I want to find out about everything!"

Adult participants: Older participants were more critical of the system, especially where they had relevant experience and/or considered themselves "art experts". Criticisms were not motivated by a lack of satisfaction with the MOBIlearn system but rather by the presumed "sacredness" of a museum like the Uffizi, which participants saw as a "special place". These perceptions became weaker as the trial went on, and a positive appreciation of, and interest in, the system began to emerge. The "art experts" were also highly critical of the information provided by the system, even when they were completely satisfied with the way it worked. The way that they used the information was, however, different from that of other participants. For example, all participants listened to audio files giving information about the artworks. However, the art experts (unlike most other participants) did not use this information to learn about the works but as a starting point for discussion, a way of kicking off a debate on artistic issues. ...

\section{Experience with systems functions and tasks}

\section{Chat}

All participants enjoyed using chat for the first time and were satisfied by the service. There was little or no need to deploy chat as a communications tool due to the limitations of the trial environment, an empty museum with a group of no more than 8 participants. Despite this, people had fun using the facility and appreciated chat as facilitating enjoyable exchanges. In many instances, participants were enthusiastic about the idea of being able to use chat if they were visiting the gallery in a large group. Participants thought that the ability to share information and to chat would be practical and thus popular. Many, especially younger participants, were keen on the idea of using the service to save, download and print conversations. They would thus have a 'textual photograph' to remind them of their visit to the museum. ...

\section{Experience with devices}

Participants received a variety of devices (either a mobile phone, a PDA, a pocket PC or a notebook) and so had different experiences during the trial. Moreover, the interface of each device was slightly different, meaning that accessibility and usability changed between devices. The pocket PC and notebook interfaces featured better usability than the mobile phone and PDA interfaces. Therefore, participants using these devices had not only inferior accessibility regarding their device, but also in terms of the MOBIlearn system as a whole. People allocated PDAs or notebooks typically sought technical support only to confirm that they were using their instrument or the system correctly. Those with a general familiarity with new technologies who were using the more accessible interfaces typically needed little training or support from technical staff. Below, we describe participant responses to the three different types of device and identify user needs.

\section{Mobile phones}

Mobile phones were the least popular and least used devices. Most participants had to repeatedly ask for assistance from technical staff. Participants found it difficult to navigate the system and to understand its capabilities. This meant that the vast majority of participants tended to interact very little either with the MOBIlearn system or with the museum exhibits themselves.

\section{PDAs}

These devices were quite popular. PDAs were much more than a "compromise between an audioguide and a mobile phone". They were perceived as providing attractive multimedia information. The 
only criticism participants had was that navigating the system proved difficult. Many people asked technical staff for help with navigation. It is worth highlighting that people using the PDA responded enthusiastically to the MOBIlearn system. They thought that MOBIlearn services offered a "little something extra". The device, however, was generally considered not particularly useful.

\section{Pocket PCs and notebooks}

These were the most popular devices. Participants given pocket PCs and notebooks used them more than users with PDAs and phones used their devices. Participants explored the functions of these devices extensively. People using pocket PCs and notebooks spent longer on their tour and had a more intensive experience than those using other devices. Young people, and especially young women, were particularly enthusiastic. They saw the devices as an extension of their personal diary or calendar, a place to write, note down appointments, play games and exchange messages. This tendency to associate the best interfaces with an object as personal as a diary, meant that notebooks and tablet PCs were well appreciated by participants. People liked using the system and were quick in learning how to use the functions provided. Participants using pocket PCs and notebooks were the most sociable, sharing their device with others and exchanging information and opinions. People with these devices worked well together thanks to the devices' ease of use, larger screen and accessible interface.

Figure \#.5: extracts from the initial evaluation report for the Museum Trial quoted with permission

\section{Dialectical relations: conflict and support in the Museum Scenario}

The semiotic learn-space for the Museum scenario is illustrated in Figure \#.6, where we use a combination of the museum scenario definition and the evaluation data to label the nodes.

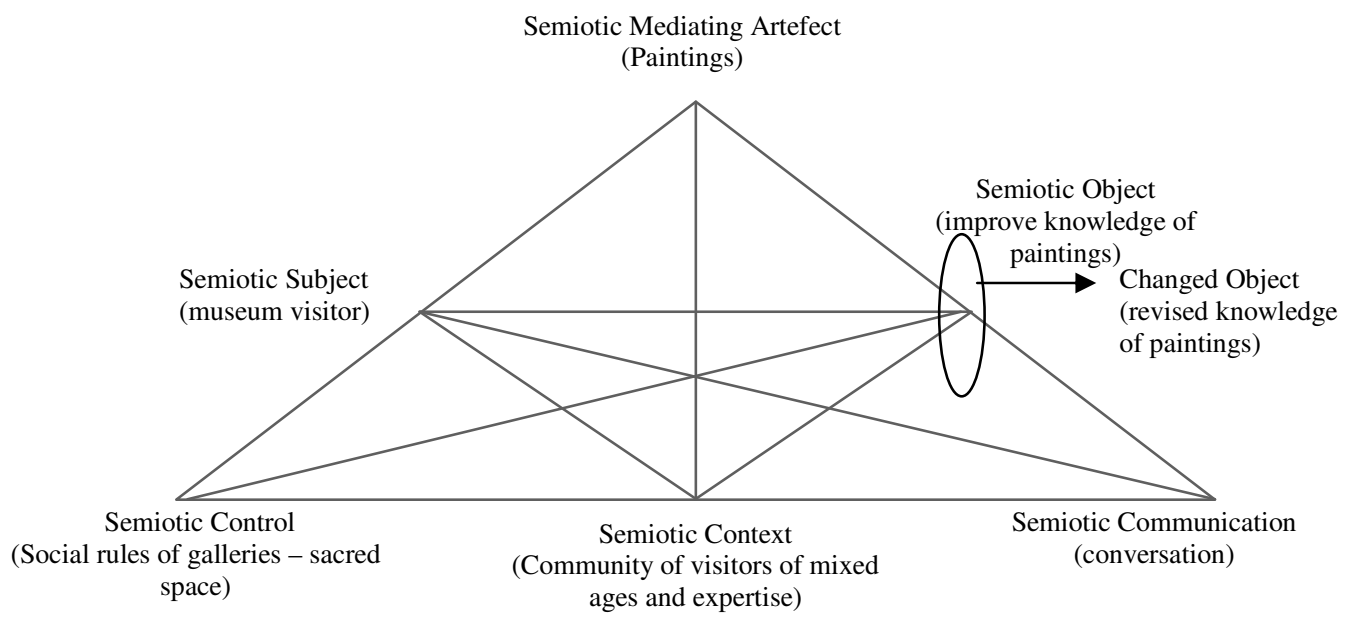

Figure \#.6: Semiotic view of the MOBIlearn Museum Scenario

The labels reflect the situation of the museum trial - the semiotic subject is a museum visitor, the social rules are those applied to gallery visiting (i.e.. a 'sacred space' with no shouting, no running, only whispered conversations etc.). The semiotic context reflects the community's mix of age and expertise. Communication would take place in the semiotic level as conversation between participants. 
The complementary technological space is illustrated in Figure \#.7.

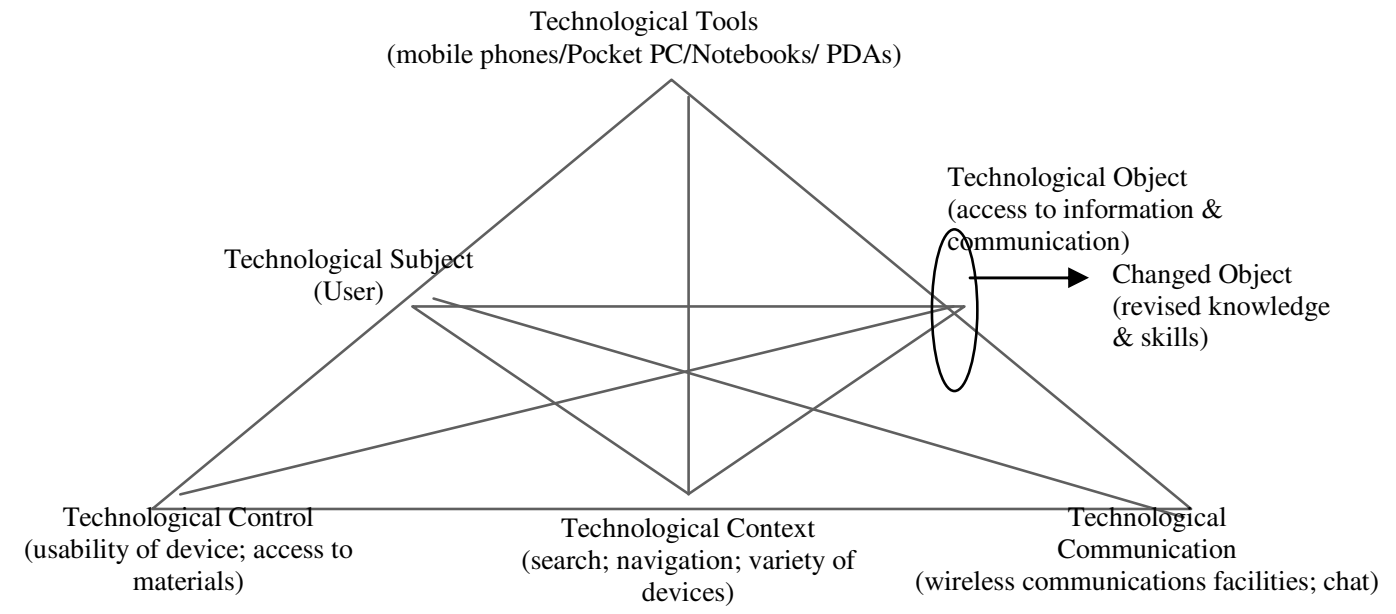

Figure \#.7: Technological view of the MOBIlearn Museum Scenario

Here we see the corresponding equivalents in the technological domain that, in principle, are meant to augment the experience in the semiotic domain. Of coursed, in cases such as this trial, where new technology is introduced, the technology not only augments the experience but can also become the object of learning for part of it. So there is an alternation in the object of learning being to better understand the paintings, to understand the new technology, and to understand how the new technology can help you better understand the paintings.

So, as in any representation of activity, the level of detail can vary. We should ideally have a representation for each of the groups visiting, as the issues of control, context and communication are different. Similarly, we need representations of the levels for each of the technological tools. Space prevents us from pursuing this level of detail.

\section{Pocket PCs and notebooks}

The dialectical relationship between control, context and communication, as well as between the semiotic and technological spaces is evident in the case where Pocket PCs and Notebooks were used. When visitors had devices with good multimedia facilities and high levels of usability, they enjoyed their experience in the museum much more. The young women in the group formed an association between them and other personal 'devices' (e.g. diaries and calendars) for whom presumably such artifacts have high value, and the levels of communication and sharing increased. 
It was particularly interesting that many younger participants were keen on the idea of using the Chat service even though it wasn't strictly necessary in the trial situation. Chat creates a conversational space within the 'sacred space' of the museum, to communicate with multiple participants without anyone else being aware.

The 'textual photograph' concept is an example of the dialectic between device and activity. It represents emergent behaviour that could not have been part of a museum experience prior to the introduction of the mobile devices.

In all these cases, the technological aspects of the scenario were supporting and augmenting the semiotic activities, contributing a much richer experience for visitors. This is represented in Table \#.2.

\begin{tabular}{|l|l|l|}
\hline Tool & Technological Space & Semiotic Space \\
\hline Subject & $\begin{array}{l}\text { Pocket PC/Notebook } \\
\text { computer }\end{array}$ & Paintings \\
\hline Control & $\begin{array}{l}\text { Experienced technology } \\
\text { user }\end{array}$ & Museum visitor \\
\hline Context & Usability --good & $\begin{array}{l}\text { Social Rules: Sacred space } \\
\text { can be respectfully de- } \\
\text { sanctified (little noise) }\end{array}$ \\
\hline Communication & $\begin{array}{l}\text { Interesting well presented } \\
\text { content }\end{array}$ & $\begin{array}{l}\text { Young people/esp. young } \\
\text { women }\end{array}$ \\
\hline Object & $\begin{array}{l}\text { Good comms facilities; } \\
\text { chat }\end{array}$ & $\begin{array}{l}\text { Exchange of information } \\
\text { and opinion; textual } \\
\text { photographs }\end{array}$ \\
\hline
\end{tabular}

Table \#.2: Support in the Museum Trial

The dialectical shaping behaviour emerging in the semiotic level in the control, context and communications nodes as a result of supporting technological underpinning becomes evident. The dialectic is occurring between all three, and from each of those to the corresponding node in the technological space.

\section{Mobile phones and PDAs}

In the case of the other technologies (mobile telephones and PDAs) we find that the relative lack of usability in the technological domain inhibits all these developments in the semiotic (Table \#.3). 


\begin{tabular}{|c|c|c|}
\hline & Technological Space & Semiotic Space \\
\hline Tool & Mobile phone/PDA & Paintings \\
\hline Subject & $\begin{array}{l}\text { Experienced technology } \\
\text { user }\end{array}$ & Museum visitor \\
\hline Control & Usability --poor & $\begin{array}{l}\text { Social Rules: sacred space } \\
\text { remains intact and is } \\
\text { violated by technology }\end{array}$ \\
\hline Context & $\begin{array}{l}\text { Difficult interface, poor } \\
\text { search }\end{array}$ & No engagement or sharing \\
\hline Communication & $\begin{array}{l}\text { Good comms facilities; } \\
\text { chat }\end{array}$ & Communication not used \\
\hline Object & No access to information & $\begin{array}{l}\text { Knowledge and skills } \\
\text { development: inhibited }\end{array}$ \\
\hline
\end{tabular}

Table \#.3: Contradictions in the Museum Scenario

PDAs tended to be 'under-used due to accessibility and usability problems'. People who were allocated phones and PDAs sought much more technical support, and, in the case of the mobile phones, tended to interact very little with the MOBIlearn system, the museum exhibits or other visitors. In this case, the technological domain is not supporting development of activity in the semiotic domain. Despite the communications infrastructure being excellent, it was simply not used because the participants never arrived at a point where it would have been useful to use it. The technological subject (the user) was in conflict with the semiotic subject (the museum visitor), resulting in an unrewarding experience.

One other aspect of the data from the trial was of particular interest. It was clear that participants valued the role of communicating with friends and colleagues in the museum. Younger people who knew less about the paintings were interested in the content provided by the MOBIlearn system, and were keen to preserve their comments and chat about them. The older, better informed 'art experts' were more critical of the content provided at one level, but it was noted by the evaluators that they used it differently. It provided the beginning of a conversation, or argument, about the pictures, which in itself is an indicator of a more mature learner (Lea and Street, 1998).

\section{Education in the mobile age}

Our aim has not been to celebrate experiential learning, nor to promote learning through informal knowledge sharing as intrinsically more valuable than institutional education ${ }^{2}$. Instead, we have attempted to explore the system of learning enabled by mobility of people and technology, though an analytic framework that does not assume either that learning arises from individual experience, nor that education only occurs in a traditional classroom mediated by a teacher. Our illustration of mobile learning was located in one of the world's great educational institutions, the Uffizi gallery, and we describe the benefits both of receiving and of discussing information provided by expert art historians. Equally, we could have explored learning on a school field trip, or by medical trainees in a hospital. 
Activity Theory can be employed to identify tensions and contradictions in activity systems which typically inhibit the subject from achieving the object of the activity. The classic example of a contradiction provided by Engeström, taken from Leont'ev (1981), is between the vocation of a doctor, who is impelled to heal the sick and make everyone well, but who also has to make a living, so must hope that people do not stop being ill. One consequence of our analysis of learning as a technology-mediated process of coming to know through conversations across contexts is that it reveals new contradictions with institutional education. These tensions do not arise from some wish by the authors to challenge formal education; they already exist in society.

A world in which children own powerful multimedia communicators and where they practise new skills of online file sharing and informal text communication does not fit easily with traditional classroom schooling. It challenges the classroom as an environment in which both the structure and content of discourse are regulated externally by the curriculum and the examinations system, and where communications are mediated by the teacher. The carefully bounded discourse of formal education contrasts with the rich interactions that children engage in outside school, through mobile calls, texting and computer messaging, and by conversing in online communities. These two worlds are now starting to conflict as children bring mobile phones into the classroom or share homework online:

...the highly significant coupling of young people and mobile technologies has not been well received in educational quarters. Alongside well-publicised health scares has been a steady stream of confusion, conflicting advice and moral panic within the media, government departments and the educational community. Debates over the rights of schools to regulate and control students' use of mobile phones during school hours still rage amidst highprofile court cases and ambiguous government guidance... Concerns over rising levels of youth crime relating to mobile technologies also proliferate, as well as more spurious issues such as cheating in examinations and truancy. Put simply, schools and the wider educational community have been caught up in dealing with the minutiae of student ownership of mobile phones without fully considering the wider implications of such mobile technologies. (Selwyn 2003, p. 132).

The analysis of learning as a conversational system might imply that a teacher has no ontologically privileged position, but is simply another participant in a continual conversation. We recognize that our theory of mobile learning does not give sufficient importance to what it is that makes a learning activity valuable, to the role of teachers in promoting effective learning, to classrooms as well-organized locations for study, and to educational institutions in extending and validating learners' knowledge. Traditional education needs to be explored in relation to the new world of global knowledge and mobile technology. It is not sufficient to assert that authoritative knowledge is always located in the specialist professions and disciplines. Nor can we say that knowledge emerging from the new conversational communities such as Wikipedia (www.wikipedia.org) is more trustworthy because it is the product of many inter-regulating minds, or invalid because it has been created through a selforganizing community rather than by a body of experts. 
Instead of seeing mobile communication and online communities as a threat to formal education, we need to explore how learning can be transformed for the mobile age, through a dialogue between two worlds of education: one in which knowledge is given authority through the curriculum, the other in which it emerges through negotiation and a process of coming to mutual agreement. Thus, Richards (2004) argues that:

... the challenge of ICT integration may be a crucial focus for educational reform in terms of productive new modes of learning which reconcile the active learner's construction of knowledge with a reinvigorated sense of teacher agency. (p. 347).

Describing learning as a process that extends beyond individuals to distributed systems that learn and develop raises issues about the ontological role of technology as a participant in learning. In distributed learning systems as they have been described here, learning and cognition are diffused. The creation of meaning lies in the act of exchange: the unique interaction that takes place between the elements of the system (humans or technology) within a distributed context. The learning system as a whole evolves in a continuum of advancing knowing through conversations and interactions. Knowledge is embodied in both the elements of the system and their interactions. At the end of a learning episode, what the elements take away is knowledge in the form of the experience of the learning system that was. This cyclic process underlies the continually changing activity systems we represent.

Finally, the view of learning as the process of coming to know through continuous conversations across multiple contexts amongst people and interactive technologies, raises the issue of where the ownership of learning lies. We argue that learning systems need to take shared ownership of learning. The agency is not with a single individual, nor with the technology; it lies in the democratic synergy between the different parts of the system with the aim to advance knowing. Learning needs to be conceptualised in terms of interactions between individuals, humans or non-humans, which take place in order to achieve evolving states of knowing as they are shaped by mutually (and continuously) negotiated goals. Such a concept, of shared ownership of the development of knowledge raises tensions with copyright and intellectual property, as is being shown in the growing Open Source (www.opensource.org) and Open Knowledge initiatives (www.okiproject.org).

The implications of this re-conception of learning, as conversations across contexts, are profound. It removes the solid ground of education as the transmission or construction of knowledge within the constraints set by a curriculum, and replaces it with a cybernetic process of learning through continual negotiation and exploration. This can be seen as a challenge to formal schooling, to the autonomy of the classroom and to the curriculum as the means to teach the knowledge and skills needed for adulthood. But it could also be an opportunity for technology to bridge the gulf between formal and experiential learning. Thus, Dewey contends:

As societies become more complex in structure and resources, the need for formal or intentional teaching and learning increases. As formal teaching and training grow in extent, there is the danger of creating an undesirable split between the experience gained in more direct 
associations and what is acquired in school. This danger was never greater than at the present time, on account of the rapid growth in the last few centuries of knowledge and technical modes of skill. (Dewey, 1916, p. 9-10)

New mobile and context-aware technology can enable young people to learn by exploring their world, in continual communication with and through technology. Instant messaging, for example, enables people to create learning communities that are both contextual, in that the messages relate to locations and immediate needs, yet unbounded since the messages can be exchanged anywhere in the world. Mobile technology can also enable conversations between learners in real and virtual worlds, such as between visitors to a museum or heritage centre, and visitors to its virtual counterpart. A person standing in front of an exhibit has the benefit of being there, of experiencing the full physical context, whereas the visitor to an online museum can call on the rich informational resources of the worldwide web. If we can design technology to enable rich conversations between these two learners-in-context, then they gain an educational experience that, in Dewey's phrase, is "vitally shared". Education in the mobile age does not replace formal education, any more than the worldwide web replaces the textbook; rather it offers a way to extend the support of learning outside the classroom, to the conversations and interactions of everyday life.

\section{Acknowledgements}

This paper has benefitted from discussion amongst members of the Philosophy of Technology Enhanced Learning Special Interest Group of the Kaleidoscope European Network of Excellence, and by detailed written responses from the members of the group to an earlier draft. We are also grateful to Chip Bruce for indicating the connection with Dewey's theory of inquiry, and to the MOBIlearn 5th Framework IST project (IST-2001-37440) for supporting extensive research into the theory and practice of mobile learning.

\section{References}

Argyris, C., \& Schön, D. (1996). Organizational learning II: Theory, method and practice.Reading, Mass: Addison Wesley.

Banks, B. (2004). E-Portfolios: Their Uses and Benefits. Retrieved 25th June, 2005, from http://ferl.becta.org.uk/content_files/ferl/resources/organisations/fd\%20learnin g/e-portfoliopaper.pdf

Berners-Lee, T., Hendler, J., \& Lassila, O. (2001). The Semantic Web. Scientific American, 284(5), 34-43.

Boyd, G., \& Pask, G. (1987). Why do instructional designers need conversation theory? In D. Laurillard (Ed.), Interactive Media: Working methods and practical applications (pp. 91-96). Chichester: Ellis Horwood Ltd.

Bristow, H. W., Baber, C., Cross, J., Woolley, S., Jones, M., (2002). Minimal Interaction for Mobile Tourism Computers. The Workshop "Mobile Tourism Support" at MobileHCI 2002. Available at http://www.eee.bham.ac.uk/pcg/docs/Mobiletourismv4.1.pdf. 
Brown, J. S., Collins, A., \& Duguid, P. (1989). Situated cognition and the culture of learning. Educational Researcher(January-February 1989), 32-42.

Bruckman, A. (2004). Co-Evolution of Technological Design and Pedagogy in an Online Learning Community. In S.A. Barab, R. Kling and J.H. Gray (eds.) Designing for Virtual Communities in the Service of Learning. Cambridge: Cambridge University Press.

Brugnoli, C., Bo, G., \& Murelli, E., (2005) 'Augmented itineraries: Mobile Services Differentiating What Museums Have to Offer' contribution to the MOBIlearn Deliverable D11.2 'Evaluation of the MOBIlearn Final System', J.Taylor, P. McAndrew (eds).

Cole, M. (1996). Cultural psychology: A once and future discipline.Cambridge, MA: Harvard University Press.

Crabtree, J., Nathan, M., \& Roberts, S. (2003). MobileUK: Mobile phones and everyday life:London: The Work Foundation.

Da Bormida, G., Bo, G., Lefrere, P and Taylor, J., (2003) An Open Abstract Framework for Modelling Interoperability of Mobile Learning Services, Procs 5th International Conference On Enterprise Information Systems (ICEIS 2003) as part of the International Workshop on "Web Services: Modelling, Architecture and Infrastructure"

Daniels, H. (2001). Vygotsky and Pedagogy.London: Routledge.

Davis, J. (2001). Conceptual Change. In M. Orey (Ed.), Emerging perspectives on learning, teaching, and technology. E-book, available at: http://www.coe.uga.edu/epltt/conceptualchange.htm.

Dewey, J. (1916). Democracy and Education.New York: Free Press.

Duffy, T.M., \& Cunningham, D.J. (1996). Constructivism: Implications for the design and delivery of instruction.In D. H. Jonassen (Ed.), Handbook of research for educational communications and technology. New York: Simon \& Schuster Macmillan, pp 170-199..

Engeström, Y. (1987). Learning by expanding: An activity-theoretical approach to developmental research.Helsinki: Orienta-Konsultit.

Engeström, Y. (1996). Perspectives on activity theory.Cambridge: Cambridge University Press.

Freire, P. (1996). Pedagogy of the Oppressed. 20th anniversary edition revised. NY: Continuum.

Grinter, R. E. and Eldridge, M. (2001). y do tngrs luv 2 txt msg?, in W. Prinz, M. Jarke, Y. Rogers, K. Schmidt and V. Wulf (eds.): Proceedings of the Seventh European Conference on Computer-Supported Cooperative Work ECSCW '01, Bonn, Germany. Dordrecht, Netherlands: Kluwer Academic Publishers, pp. 219-238.

Hickman, L. (1990). John Dewey's Pragmatic Technology.Bloomington: Indiana University Press.

Illich, I. (1971). Deschooling Society.London: Calder and Boyars.

Kim, A.J. (2000) Community Building on the Web, Berkeley, Ca.: Peachpit Press.

Knowles, M. S., \& Associates. (1984). Andragogy in Action. Applying modern principles of adult education.San Francisco: Jossey Bass.

Laurillard (2002). Rethinking University Teaching: A Framework for the Effective Use of Learning Technologies, 2nd ed. London: Routledge Falmer.

Lea, M \& Street, B (1998) Student writing in higher education: An academic literacies approach. Studies in Higher Education. 23 (2): 157--172 
Leadbetter, C. (2005). Learning about Personalisation: how can we put the learner at the heart of the education system?. Retrieved 25th June, 2005, from

http://www.standards.dfes.gov.uk/innovationunit/pdf/Learningaboutpersonalisation.pdf?version=1.

Leont'ev, A. N. (1981). The problem of activity in psychology. In Wertsch, J. V. (Ed.), The concept of activity in soviet psychology, 37-71. Armonk, NY: M. E. Sharpe.

Lonsdale, P., Baber, C., Sharples, M. (2004) A Context Awareness Architecture for Facilitating Mobile Learning. In J. Attewell \& C. Savill-Smith (eds.) Learning with Mobile Devices: Research and Development. London. Learning and Skills Development Agency, pp. 79-85.

Lonsdale, P., Baber, C., Sharples, M., Costicoglou, S., Pouliakis, A. and Mason, J. (2003) MOBIlearn Context Awareness Subsystem Specification: Literature Review, Proposed Architecture, and Pre-Prototype Demonstrator, MOBILearn Project Report D6.1. University of Birmingham: MOBIlearn IST Project.

Naismith, L., Sharples, M., \& Ting, J. (2005) Evaluation of CAERUS: a context aware mobile guide. In H. van der Merwe \& T. Brown, Mobile Technology: The Future of Learning in Your Hands, mLearn 2005 Book of Abstracts, 4th World Conference on mLearning, Cape Town, 25-28 October 2005. Cape Town: mLearn 2005, p.50.

National Research Council. (1999). How people learn: Brain, mind, experience, and school.Washington, DC: National Academy Press.

Pask, G. (1975). Minds and media in education and entertainment: some theoretical comments illustrated by the design and operation of a system for exteriorizing and manipulating individual theses. In R. Trappl \& G. Pask (Eds.), Progress in Cybernetics and Systems Research (Vol. IV, pp. 38-50). Washington and London: Hemisphere Publishing Corporation.

Pask, G. (1976). Conversation Theory: Applications in Education and Epistemology.Amsterdam and New York: Elsevier.

Ravenscroft, A. (2000). Designing Argumentation for Conceptual Development, Computers and Education, 34 (2000), 241-255.

Rheingold, H. (2002). Smart mobs: the next social revolution.Cambridge, MA: Perseus Publishing.

Richards, C. (2004). From old to new learning: global imperatives, exemplary Asian dilemmas and ICT as a key to cultural change in education. Globalisation, Societies and Education, 2(3), pp 337--353.

Selwyn, N. (2003). Schooling the Mobile Generation: the future for schools in the mobile-networked society. British Journal of Sociology of Education, 24(2), pp 131--144.

Scott, B. (2001). Gordon Pask's Conversation Theory: A Domain Independent Constructivist Model of Human Knowing. Foundations of Science, 6(4), 343 360.

Shannon, C. E., \& Weaver, W. (1949). The mathematical theory of communication.Urbana: University of Illinois Press.

Sharples, M. (2003). Disruptive Devices: Mobile Technology for Conversational Learning. International Journal of Continuing Engineering Education and Lifelong Learning, 12, 5/6, pp. 504-520.

Sharples, M. (2003b). Imagine a future where buildings or public spaces are 'learning enabled'. Elearning Europa Info, $20^{\text {th }}$ January 2003. Available at 
http://82.194.71.130/index.php?page=doc\&doc_id=593\&doclng=6\&menuzon $\mathrm{e}=1$

Taylor, J (2004). A task-centred approach to evaluating a mobile learning environment for pedagogic soundness in: J. Attewell \& C. Savill-Smith (Eds) Learning with mobile devices (Learning and Skills Development Agency) 167 $--171$

Traxler, J. (2005). Using Mobile Technologies to Support Learning in Sub-Saharan Africa. In H. van der Merwe \& T. Brown (Eds.), mLearn 2005: Book of Abstracts (pp. 66). Cape Town: mLearn 2005.

Vavoula, G., (2005) A Study of Mobile Learning Practices, Internal Report, Deliverable 4.4 for the MOBIlearn project (IST-2001-37440)

Vavoula, G.N., \& Sharples, M. (2002). KLeOS: A personal, mobile, Knowledge and Learning Organisation System. In Milrad, M., Hoppe, U. Kinshuk (eds.) Proceedings of the IEEE International Workshop on Mobile and Wireless Technologies in Education (WMTE2002), Aug 29-30, Vaxjo, Sweden, p. 152156.

von Glaserfeld, E. (1984). An introduction to radical constructivism. In P. Watzlawick (Ed.), The invented reality (pp. 17-40). New York: Norton.

Vygotsky, L. S. (1978). Mind in society: the development of higher psychological processes.Cambridge: Harvard University Press.

Waycott, J. (2004).The appropriation of PDAs as learning and workplace tools: an activity theory perspective. Unpublished PhD Thesis. The Open University, UK.

Winograd, T. \& Flores, F. (1987) Understanding Computers and Cognition: A New Foundation for Design, (220 pp.) Norwood, NJ: Ablex, 1986. Paperback issued by Addison-Wesley, 1987

\section{Notes:}

1. The description given is adapted from:

http://www.edu.helsinki.fi/activity/pages/chatanddwr/activitysystem/ accessed 25/11/05

2. This section has been informed by responses from members of the Philosophy of Technology Enhanced Learning Special Interest Group of the Kaleidoscope European Network of Excellence, in particular the commentary from Michael Young. 